\title{
TRIZ Inventive Principle in the Creative Process of Textile Products
}

\author{
da Silva de Santis $\mathrm{SH}^{1 *}$, Franco $\mathrm{B}^{1}$ and Marcicano CJPP ${ }^{2}$ \\ ${ }^{1}$ University of Campinas, Campinas, Brazil \\ ${ }^{2}$ Univesity of São Paulo, Brazil
}

\begin{abstract}
The work was developed based on the concepts of the theory TRIZ (theory of Inventive Resolution) that was used to assist the creative process of the design of a technological fabric. It was evaluated the application of the concepts of sustainability for the design as an inventive principle. As a result, it was obtained various design alternatives working with the functions and requirements of the fabric.
\end{abstract}

Keywords: TRIZ; Process creative; Medology design

\section{Introduction}

The problems presented in this study joins the fabric development and the creative process ensuring the use of resources in an appropriate manner. Product development in textile industry and associates processes with creativity are part of the creative economy. The creative economy gathers a set of social entities focused on the development of creativity, culture, knowledge, media, arts, design and other linked to culture and creativity $[1,2]$. The growth of research in this area has provided an increase in technologies and incentives for creativity.

Industrial textile products which have a booming and very competitive market (market of fashion), these products need methods and instruments compatible with the necessary quality. The project methodology is concerned with providing an efficient scheme of production of goods and service that promotes the reduction of environmental impacts, increase internal controls and rapid realignment in the case of failures. The procedures for product design and management are important as an instrument in the production process.

Thus, the tools used to improve product design, increase of quality in processes and sustainability. In this respect, the evidence of validation for the premise is carried out by means of a case study in a textile manufacturing company.

\section{Proposed Methodology}

The proposed methodology for the product design begins with the use of mind mapping creation techniques after the theory TRIZ associated with design tools are utilized to create a model of stimulus to the creative process. The model establishes the analysis proposed in theory by means of idealization, contradiction, and resources for the creation of a technological fabric which can switch the composition to generate innovative products through functionality. In the first step develops the mental model from the object to the features, this stage is the description of the requirement.

The study demonstrates the existing relations and associations also met a group to identify the priorities of the characteristics of the fabric and the principles of TRIZ, showing what principles to assist in the construction of the technological knitted fabric. To do this, it was compiled a matrix that prioritizes the basic principles for creating a process that encourages creativity in the design of the textile product. In the second stage, the design project with the characteristics and the design sketch demonstrating the purpose. In the model, it was used tools to analyze the functions of the product, discover the main features of the object through the morphological framework of the knitted fabric technology.

\section{TRIZ (Russian acronym for theory of inventive problem- solution)}

According to Carvalho and Back [3], the narrow escape by Altshuller [4] had as object of study the patents of this period, aiming to seek creative solutions to problems of intuitive method. MeanShen [5] explains that the TRIZ was developed for application in inventive solution of problems because, although different methods in different areas of knowledge (Administration, advertising, arts), this methodology was born in engineering with the original purpose of developing a method to invent.

Carvalho and Back [3] and Mean-Shen [5] claim that the TRIZ promotes idea generation through structured tools, mainly by encouraging creativity.The concept works the ideality, desired and undesirable functions, contradictions between the requirements and the needs of the object, in addition, the system features (everything that is necessary for the performance of the product) and alternating the same for troubleshooting the system.The TRIZ is a structured procedure for innovation and creativity. With her, organizations will not need to hire "inventive geniuses" or be awarded solely on intuitive human processes to solve their problems.

Mean-Shen [5], Chai et al. [6] Rucht and Livotov [7] explain that this concept promotes analysis of the inventive principles by proposing the best use to produce through the idealization, contradiction, and resources. Consists of switch components of object seeking to encourage the creative process. The TRIZ is based on the 40 inventive principles that were used for modification and encourage the creative process, presents the principles through Table 1 adapted from Carvalho and Back [1]:

The principles translate the object property by encouraging the creative process, through amendment to encourage creativity. In this way, the principles should be used to contribute to the process

${ }^{*}$ Corresponding author: Sandra Helena da Silva de Santis, University of Campinas Campinas, Brazil, Tel: 5511994680410; E-mail: Brasil-s.h.santis@hotmail.com

Received December 15, 2016; Accepted December 23, 2016; Published December 27, 2016

Citation: da Silva de Santis SH, Franco B, Marcicano CJPP (2016) TRIZ Inventive Principle in the Creative Process of Textile Products. J Textile Sci Eng 6: 279. doi: 10.4172/2165-8064.1000279

Copyright: (c) 2016 da Silva de Santis SH, et al. This is an open-access article distributed under the terms of the Creative Commons Attribution License, which permits unrestricted use, distribution, and reproduction in any medium, provided the original author and source are credited. 


\begin{tabular}{|c|c|}
\hline Principles of TRIZ & Principles of TRIZ \\
\hline 1. Segmentation & 21. Dispatch quickly \\
\hline 2. Extraction & 22. Turn prejudice into profit \\
\hline 3. Quality in & 23.Feedback \\
\hline 4. Asymmetry & 24. Mediation \\
\hline 5. Union or Mixture & 25. Self Service \\
\hline 6. Universalization & 26. Copy \\
\hline 7. Alignment & 27. Object use descartes \\
\hline 8. Balance & 28. Replace the mechanical means \\
\hline 9. Prior Compensation & 29. Use pneumatic or Hydraulic \\
\hline 10. Prior Action & 30. Use of thin films or membranes \\
\hline 11. Cushioning or protection provided for & 31. Use porous materials \\
\hline 12. Equipotential bonding & 32. Color change \\
\hline 13. Reversal & 33. Thermal voltage \\
\hline 14 Change shapes & 34. Disposal and regeneration \\
\hline 15 Promotion & 35. Change in physical state or \\
& chemical \\
\hline 16. Partial or Excessive action & 36. Phase transition \\
\hline 17. Changing dimension & 37. Thermal Expansion \\
\hline 18. Vibration & 38. Use of strong oxidizers \\
\hline 19. Periodic Action & 39. Using inert atmosphere \\
\hline 20. A useful action continuity & 40. Use of composite materials \\
\hline & \\
\hline
\end{tabular}

Table 1: 40 inventive principles.

of creation, so that the manufacture becomes more competitive and thus, promotes a series of methodologies based on the application of tools for innovation and creativity, supporting the idea that the creative process can be augmented through new methods and instruments. It also encourages the thinking in the use and disposal of the product in your development, promotes the sustainable development of the product [8].

\section{Sustainability}

The TRIZ establishes a set of measures that modify the object through Division of functions, coordination of actions, changing colors, functionality, weight and cost reduction. The analysis of the benefits of the product, component separation and verification of use and disposal. Smith [9] States that the characteristics of lean manufacturing can be defined as flexibility, reduction of constraints, such as the time of setup, or product, specialized tools, and techniques to improve production. Botero [10] comments that this philosophy aims to reduce costs and increase the company's results through the application of quality tools in the processes. Within this context, the Union of philosophy with the technique creates a template to give the necessary support to the manufacturing and creative incentive to avoid waste, cost, and non-conformities.

Porter [11] States that the increase in performance or activities change modifies the value to the buyer (customer), this includes the functionality to the product. Yet, according to the author the identification of worthwhile activities require the grouping criteria or dismemberment by categories. Thus, identification of the features of the product or process should consist of an analysis, a thorough examination of the system, process and procedures by determining its functions.

To manufacture becomes more competitive it is necessary to act upon the challenges faced by the market more and more demanding and competitive in a globalized world. The ecosystem is the environment in return for everything and the company. The system in this example is the company, your organization, its components, and its structure. The subsystem is the departments that are part of the company and that, although each has its function, we have to work with the unification of ideas and thoughts. All join in a synthesis, it means that one must dialog the system since all components must engage each other for there to be unification. The management system must be prepared to respond appropriately, in this sense; the tools should give the necessary support to develop operational strategies of quick answers and simple.

It is important to outline goals involving contributions to organizational sustainability. One of the main goals of the globalized companies is to make the sustainable company through operational models. A manufacturer must promote the management of activities in order to achieve the operational capacity of its production the technique came about due to the shortage of raw materials during World War II, Csillag [12]. Researchers such as Juran [13], Campos Falconi [14] state that new technologies for products and manufacturing processes have created the need to invest in strategies to improve quality controls. In General, companies have problems to keep up with the market requirements, innovations and transformations. Many large how many small firms seek solutions [15].

Many companies are looking for solutions that can be tailored to your needs momentary. Manufacturing companies to carry out their activities require a management system targeted for improvement in production, performance, and reduction of losses [16,17]. The TRIZ offers alternatives to modify and change the creative process and proposes troubleshooting complexity through the inventive principles; the theory suggests significant changes by changing the composition, exploring the physical state, replacing forms and components. The variables in the creative process due to the complexity in creating require flexibility. The flexibility serves as a preposition as creativity has many decision-making process variability, uncertainty, complexity, and ambiguity because it is a choice that is based on the information. Therefore, the theory of inventive resolution brings a change to recreate, modifying the proposed object.

\section{Creative process}

The man has his creative manifestations through their individual aspirations, thoughts, and idealization. The need is a motivating factor that drives to the pursuit of knowledge, and satisfaction problem solution. To Lobach [18] the human being is also addressed by multiple and varied needs. The appearance of needs is not always logical, especially when other activities or processes have an occasional preference. The need to demand satisfaction, aspiration is the desire to get something spontaneous to prove the idea or the preview. Aspiration is the desire to get something that may or may not be achieved. The needs and follow the evolution of technology, the instruments of information and economic development.

Lobach [18] states that the design consists of a project, plan or systematic method that includes the solution of a problem incorporating ideas, innovation, creation of sketch, samples, templates to make the concrete solution. Over the centuries, the needs in their evolution have been accompanied by the development of tools, methods, and systems. The constant development through research and events show that the innovative creativity has had a key role. In this sense, the study of the methodology for the development of the creative process entered a logical and rational thinking in human evolution. The development of human creative process has also been marked by various frustrations, problems in creativity and innovation, these problems are reported consistently by various scholars.

A number of scholars and researchers [19-21] have already been 
attacked by creative inertia, the difficulty of exposing ideas, fears, lack of innovation or even problems that seemed intractable.

\section{Product Development}

Ostrower (20) States that the ability to understand, assimilate, configure and mean is the creative act.Create is a way of establishing a new relationship between the human mind and the object in order to understand the meaning or resign (give a new meaning, a new practice, ability to perceive an object for a different view). Already the creative process derives from the structure of cognition (knowledge of the facts), intelligence (human feature composed of logical thinking, communication, knowledge, wisdom, problem-solving, emotional control, etc.), ability to create (make sense of something or resign something) and innovation (create an unknown). To meet the new type from the consumer and social changes, the manufacturers seek to align existing requirements with the functionality and aesthetics creating values that can be applied to technological fabrics.

Barbará [8] style process as a set of ordered and integrated actions for a specific production order at the end of the cycle they generate products, services or information. In the manufacturing process with synthetic fibers began the 30, developed fibers become part of the manufacture of textiles and clothing. To give a small notion of what we call, I find it interesting the context of early history, remembering some key facts. In this sense, manufacture textile manufacturing uses the fibers to form the yarn and yarn weaved turns into the fabric. Manufacture textile production divided into three cores: the manufacture of yarn, fabric manufacturing, and clothing manufacturing.

According to Sanches [21-23], the fiber is the smallest element of the composition of the fabric in any natural or manufactured substance that has the appropriate features to allow its processing. Being the smallest component of hairy nature, that can be extracted or separated from a fabric. In the manufacture of yarn, the process of creation establishes the mixture of materials for processing. The processing consists of a rational part that modifies the form of a structure or system for the construction of a mixture, an irrational part that is gathering emotional, psychological aspects, innovative, creative and personal. This means that the transformation depends on the creative aspects to innovate in fiber mixture.

The procedure of creation promotes find strategies by encouraging the production of new ways of mixing the components, which can motivate, add capacity and add value to the basic functions and the secondary product or service to generate probabilities of more interactive information on the market. The set of productive or manufacturing operations must have as its main focus for improvement, the increase in productivity and quality. On an industrial scale (scale of manufacturing) in the contemporary good job of project methodology presents some techniques that promote encourage creative procedures, in short demand accommodating customer demand. The application processes of design methodology consist in the interaction of instruments, resources and converted into energy that carries out the connection between procedures and tasks.

The manufacture of textile manufacturing that is the object of study of this research produces knitted fabric, working in the field of circular knitting, among his articles produced are knitted fabric for fitness and beach. The knitting textile manufacturers that also serve as object for this research have a tradition in Brazilian economy, and considered as one of the major manufacturing sectors in Latin America, composed of several business units in the country, their most common products made in fabric composed of combinations of polyamide, cotton and spandex (synthetic filament) in circular and rectilinear knitting machines. The study used the knitting on circular knitting machines, which is a reference to continue previous work by the author.

The Knitting is considered a reference in the textile area for development in more than 70 years of tradition, the sector considered of high growth in recent years, and this is due to the intensification of studies in the area. Offers cutting-edge and diverse resources in the development of the textile industry. The industry serves a reference for dealing with large organizations and major mark as Rhodia, Valiseré, Santos and others. Organizations have become increasingly flexible in its processes, mainly by using strategic factors that can motivate, add the ability to add value and basic functions and secondary goods production to provoke more interactive participation opportunities in the market. According to Agostinho [4] the search for competitiveness has several methodologies, scientific concepts, technologies for improving the organization.

This demand from the market has caused changes in organizations, so they are more flexible and dynamic in their structure, system and organizational model. The business system consists of a set of actions with its transformation to answer internal and external pressures to market, a logical reaction from the consumer needs, in short, an entity that by producing goods with or without profit. The actions constitute a form of planned processes that are linked in a virtual or physical structure. Processing (Figure 1) establishes a set of ordered processes in operations for modifying the resources in products to Agostinho [4]

The establishment of roadmaps and manufacturing processes secure manufacturing knowledge, or how to make, and is considered the cornerstone of fixing the knowledge of manufacturing. In sequence to the roadmaps and manufacturing processes, determines the time required for each operation of the script accordingly and set pieces that make up the product.

The manufacturing processes interrelate in a chain of interdependent functions that considers the independent variables (external environment) and the dependent variables (internal environment). This functional interrelation facilitates the systematization of production of goods and services. Each function has a sequential operation flow for the development of an operation from the resource entry to the exit of the goods or services. The set of actions in the supply chain shows the sequence of operations that is established for the construction of a product, a commodity or a service and this facilitates the understanding of the production system. Thus, it presents the results of the application of TRIZ.

\section{Result and Discussion}

Part of analysis of characteristics of the product in relation to the items noted by principles of TRIZ. In this sense, the creation of the design of the intelligent fabric product analyzes the potential required for the product, and it is used to prioritize needs factors correlating with the principles of TRIZ theory. In this way, review what the important criteria that are applied in the development of the product to stimulate creativity. We used the methodology of focus groups.

For prioritizing employed the brainstorming with the components of the Group (engineer, production engineer, Product Design, Teacher, Designer, etc.), a classification of the principles by the degree of importance of the factors and devised the correlation matrix. The brainstorming provides a more democratic climate doesn't just drive the freedom to the expression of ideas, but also allows greater opportunities 


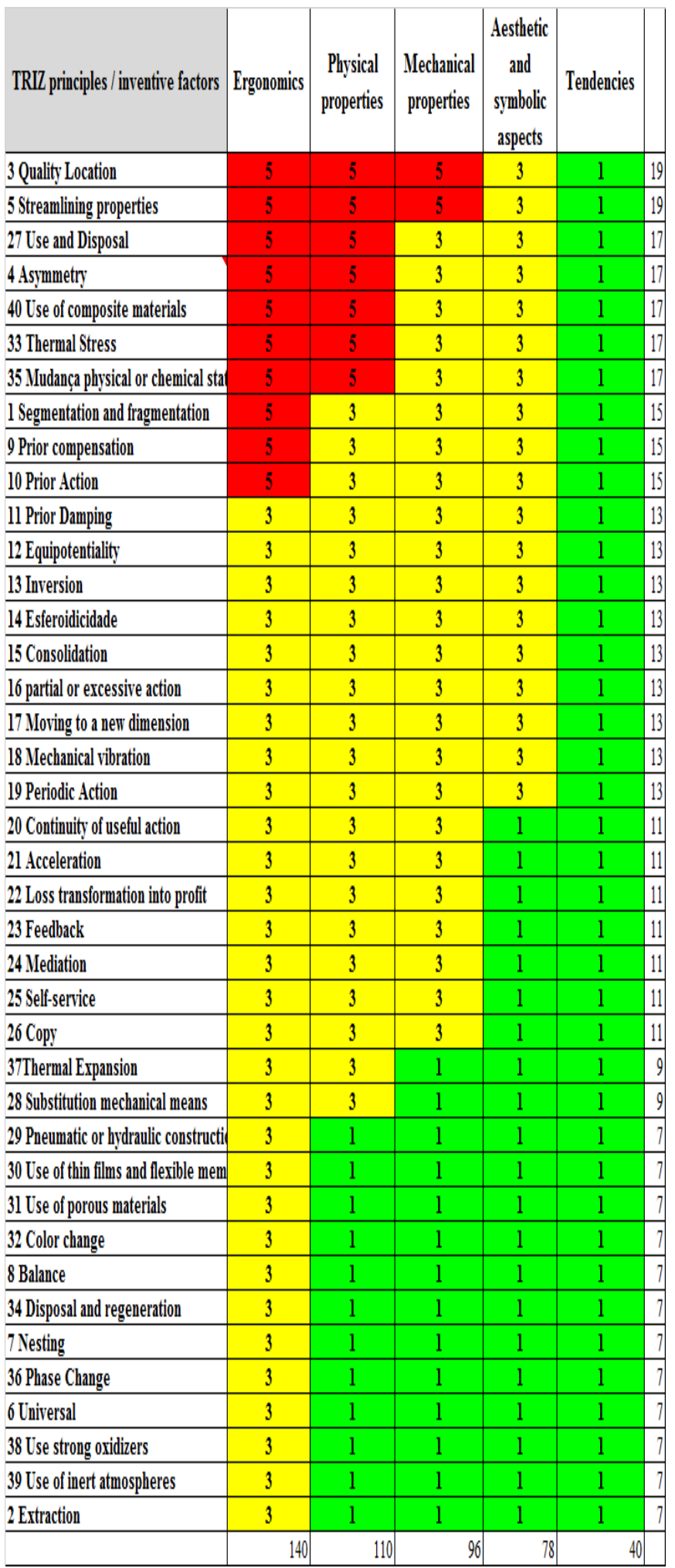

Source: Santis (2016)

Figure 1: Prioritization matrix.

for the emergence of a cross-functional knowledge, preventing the members solve the problems so focused and isolated. With the use of the correlation matrix can prioritize necessary resources and establish important criteria for product development.

The array is equivalent to the discussion to check the items that should be prioritized in the creation of the product, what must be done to stimulate new ideas to technology innovation in fabric, properties that can differentiate and increase the value for the consumer. Under this section, an array created with the essential properties and parameters of the theory. In the first meetings discussed the importance of each factor in the development of intelligent fabric (Table 2):

The criteria were organized by assigning each note corresponds to a color (Figure 2):

- Note 5-red color corresponds to high priority;

- Note 3-yellow the average priority;

- Note 1-green for low priority.

With the use of the correlation matrix, it was possible to prioritize the features required by establishing the necessary resources. The first array was organized with many priorities because each element of the Group prioritized back to your experience and hasn't noticed what really was important to the creative process. In this model include the prioritization of activities that can encourage the creative and innovation process, starting from the modifications that can be made in the design of the fabric.

The array was accomplished through the methodology of focus groups consisting of a discussion group on the main properties and how it can change the fabric creating a differentiated customer value. The first attempts resulted in an array, but the priorities were many and this made the vision of what really should be done. In this way, a consensus was reached to make a new vote to narrow the criteria and approach a more decisive result of the priorities. After all, not everything can be a priority.

Prioritization matrix (Figure 1) defines the characteristics that can be changed to create customer value, technical, ergonomic factors, and properties. The value associated with the criteria of the TRIZ has for purpose to enter the best use taking account of the specifications required by the market. The alignment from this correlation has the purpose of promoting options for modification by creating value and functionality to the fabric. Understand the relationship between the characteristics of the TRIZ methodology and technological fabric promotes the understanding of solutions to problems and possibility of the redesign of the object. The functionality of the fabric can be changed, that promotes innovation in usability, the fabric may acquire new functions and benefits.

The TRIZ generates a comparison of the properties, characteristics, and needs, designing the possibilities of applying each principle identified by promoting a change of items.

The array defined as key features for application of TRIZ respectively: the quality location, streamlining of the properties, use, and disposal, asymmetry, the use of composite materials, thermal, voltage change of physical state, segmentation and fragmentation,

\begin{tabular}{|c|c|}
\hline Correlation & Criterion \\
\hline Strong & 5 \\
\hline Average & 3 \\
\hline Weak & 1 \\
\hline
\end{tabular}

Source: adapted from Agostinho (2012)

Table 2: Criteria for classification. 
provided compensation and action envisaged. This characteristic of whisker, when applied to technological fabrics, encourage the creative process, is it possible to find solutions through modification of the properties of the knitted fabric.

The characteristics of the fabric may be crossword puzzle with the principles providing these materials changes can be: in thermal properties (absorb heat or turn up the heat, cool or heat), physical properties (have the stipulated format or preset), mechanical properties (conductive circuits of information, perform stimuli, activate electrically conducting elements, etc.), aesthetic aspects (change of colour, shape memory, outline the body, etc.) and fashion trends.

The graph you can see that only $10 \%$ of the correlations must be prioritized, the other correlations were considered a medium priority and low priority are practically representing only a difference of $6 \%$, and the average priority appears with $48 \%$ and the low priority with $42 \%$. Ergonomic characteristics, physical properties, and mechanical properties are more important than the aesthetic aspects and tendency as fabric because these characteristics are important for objects.

TRIZalready offers possibilities of modification of the properties, characteristics when applied provides the new combination. Each one of these principles is a possibility of modification of the fabric, which consists in a possibility of a change of the functionality and value of the product. These aspects are relevant in the creative process of technological fabric because they can provide options for product development. To demonstrate the possibilities of changes using the morphological framework applying the possibilities offered. The technological fabric analyzed features properties that should be highlighted in the project, providing greater visibility of the expected results and resources.

The creative process this case was encouraged by the systematic analysis of the project of construction and properties of the fabric. The same technological fabric was analyzed for morphological framework Figure 3 , the same provides a different perspective to the creative process.

You can see that with this morphological framework can make various combinations and thus create different types of technological fabrics with treatment. The morphological framework provides an option to change the object, in this context, it is noted that the technological fabric can be: according to Dedini (2007), this method was developed by Fritz Zwicky consisting of decomposed the global problem in partial problems (or parameters). The Board assists in creative development analyzing the problem through the deconstruction of the object and thus encouraged to creative thinking.

\section{Final Considerations}

The work was developed based on the concepts of the theory

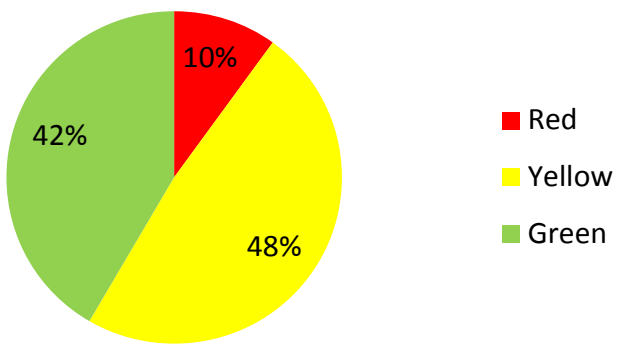

Figure 2: Priorities in percentage.

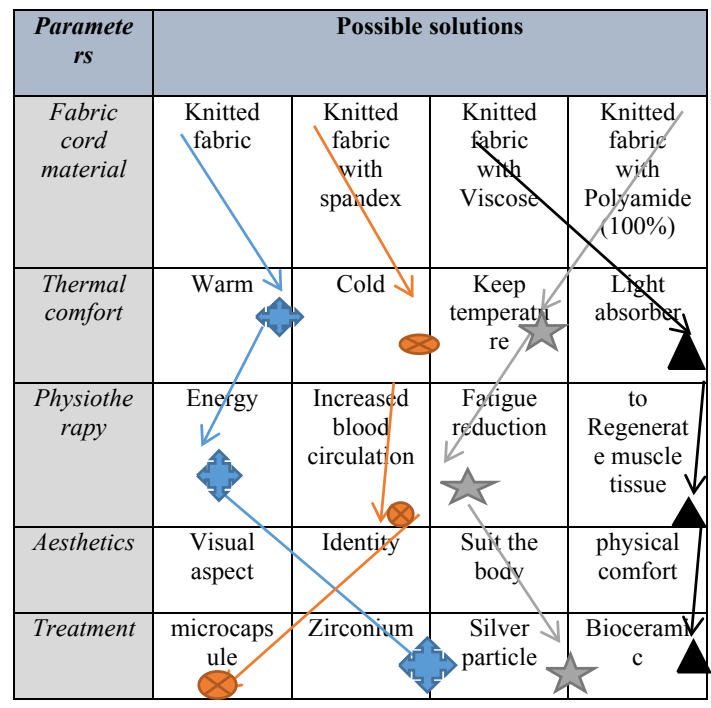

Source: Santis (2016)

Figure 3: Morphological Framework.

TRIZ (theory of Inventive Resolution) the proposal got an incentive to the creative process and evaluate the implementation of the project methodology and tools for the technological fabric designer. The study obtained various alternatives working with the functions and requirements of the fabric, we analyzed the functions through an array. Notice that the array provides build options for the development of new technological fabrics modifying features, functionalities and adding value to the object. This sustainability associated with the better use of resources, which must include the product disposal. One can notice that the tools used must provide an analysis of the properties and indicate possibilities to recreate changing the structure, functionality, and composition.

Resources are elements that make up the situation, or your environment, which can be mobilized to solve or contribute to solving a problem. They can be defined as any element of that helps to compose the system under examination or to the surroundings that were used to perform useful functions. Project methodologies make up part of the strategies to improve the creative process. The job must provide the solution for innovation and creativity, and also to problems of conflict between necessity and usability. The tools applied to the creation process must use the skills, research, and exploration of ideas by means of the methodology, thereby offering new alternatives to the process. Therefore, the use of these tools expands and organizes the creative process working with creativity and innovation.

\section{References}

1. Machado RM (2009) Da indústria cultural à economia criativa. Alceu Rio de Janeiro 9: 83-95.

2. Pires VS, Albagli S (2009) Estratégias empresariais, dinâmicas informacionais e identidade de marca na economia criativa.

3. Carvalho, Aurélio M, Nelson B (2001) Uso dos conceitos fundamentais da TRIZ e do método dos princípios inventivos no desenvolvimento de produtos. In Congresso Brasileiro de gestão de desenvolvimento de produto.

4. Agostinho OL (2012) Sistemas de Manufatura. Apostilas de Curso. Universidade Estadual de Campinas.

5. Mean-shen I (2011) The study of green product design and development by applying triz innovation principles. African Journal of business management 5: $7740-7754$. 
Citation: da Silva de Santis SH, Franco B, Marcicano CJPP (2016) TRIZ Inventive Principle in the Creative Process of Textile Products. J Textile Sci Eng 6: 279. doi: 10.4172/2165-8064.1000279

6. Chai KH, Zhang J, Tan KC (2005) A triz-based method for new service design. Journal of service research 8: 48-66.

7. Ruchti, B, Livotov $P$ (2001) Triz-based innovation principles and a process for problem solving in business and management. The Triz journal 1: 677-687.

8. Barbará SE (2011) Gestão por Processos. Rio de Janeiro: Qualitymark.

9. Bezerra GM, Martins SB (2013) Equação da ergonomia no design de vestuário: espaço do corpo. modelagem e materiais.

10. Botero, Gómez PA (2010) Lean Manufacturing: flexibilidad, agilidad y productividad. Gestión and Sociedad 3: 88.

11. Porter ME (1996) Vantagem competitiva: criando e sustentando um desempenho superior. rio de janeiro: campus.

12. Csillag, Mario J (2012) Análise do valor: metodologia do valor: engenharia do valor, gerenciamento do valor, redução de custos, racionalização administrativa.

13. Juran, Joseph M (2004) A qualidade desde o projeto: novos passos para o planejamento da qualidade em produtos e serviços. são paulo: ed. pioneirathomson learning.

14. Campos, Falconi V (1992) Controle da qualidade total. Rio de Janeiro: Fundação Cristiano Ottoni.
15. Dalla CA, Souza-Santos ED (2011) Economia criativa: novas oportunidades baseadas no capital intelectual. economia and tecnologia Curitiba ano 7: 179-186.

16. Mesquita, Melissa (2001) Competências para melhoria contínua da produção: estudo de caso em empresas da indústria de autopeças. dissertação (mestrado em engenharia de produção) - Universidade Federal de São Carlos São Carlos.

17. Dedini FG (2007) Projeto de sistemas mecânicos. apostila do curso em 964 da Faculdade de engenharia mecânica da Unicamp. Engenharia mecânica, universidade estadual de campinas, campinas.

18. Howkins J, Griesi A (2013) economia criativa. São Paulo.

19. Menegucci F, Martins E, Menezes M, Santos F, Abilio (2012) Experimentações têxteis e inovação no design de moda. in: $8^{\circ}$ Coloquio de moda, Rio de Janeiro.

20. Ostrower F (1978) Criatividade e processos de criação.

21. Sanches, Regina AP (2010) tecnologia aplicada nos artigos de vestuário destinados à prática de esportes.

22. Santis SHS (2016) $6^{\circ}$ Encontro Nacional de Pesquisa em Moda (ENPModa) and Fashion Colóquio São Paulo. Universidade de São Paulo (EACH).

23. Santis SHS (2016) Project Metodology Applyed to Smart Fabrics. Journal of Textile and Fashion Technology 2: 7-1. 